\title{
Anatomical lung shunting in pulmonary fibrosis
}

\author{
WARREN C MILLER, JOHN G HEARD, KENNETH M UNGER, DENNIS M SUICH
}

From the Humana Pulmonary Center, Webster, Texas, USA

ABSTRACT Eleven patients with cryptogenic fibrosing alveolitis were evaluated for the presence of pulmonary shunting by injection of radiolabelled particles of macroaggregated albumin larger than $10 \mu \mathrm{m}$ in diameter and by body scanning with a gamma camera. The mean shunt of $9 \%$ (SD $2 \%$ ) in the patients was not significantly different from the mean shunt of $7 \%(2 \%)$ measured in 10 normal controls. These findings suggest that shunting is not an important part of the gas exchange abnormalities noted in such patients.

Arteriovenous channels larger than normal pulmonary capillaries have been found in the lung in patients with hepatic cirrhosis and with chronic obstructive lung disease. ${ }^{1-3}$ This abnormal vasculature has been evaluated by quantitative radionuclide techniques. These enlarged vessels are believed to play a part in the genesis of hypoxaemia in these disorders. In cirrhosis a constellation of disturbances may occur, including decreased lung diffusing capacity, aggravation of hypoxaemia by exercise, and an apparent shunt like mechanism. ${ }^{4}$ The findings are similar in chronic obstructive lung disease, and the magnitude of the radionuclide shunt is correlated with the decrement in diffusing capacity. ${ }^{3}$ In chronic obstructive lung disease aggravation of hypoxaemia by exercise is correlated with loss of diffusing capacity. ${ }^{5}$ Decreased diffusing capacity and aggravation of hypoxaemia with exercise are also characteristic of pulmonary fibrosis, ${ }^{6}$ and these findings are themselves correlated in pulmonary fibrosis. $^{7}$ A common underlying mechanism in the form of enlarged alveolar vessels might be present in all these disorders. We have studied patients with pulmonary fibrosis for evidence of the presence of abnormal pulmonary vasculature.

\section{Methods}

Macroaggregated albumin particles tagged with $3 \mathrm{mCi}$ of technetium $99 \mathrm{~m}$ were injected intravenously with the patient in the supine position. The radioactivity distributed to the brain, kidneys, and lungs was measured with a gamma camera. Acquisition of counts was begun dorsally 10 minutes after injection with

\footnotetext{
Address for reprint requests: Dr Warren C Miller, Humana Pulmonary Center, 500 Medical Center Boulevard, Webster, Texas 77598, USA.
}

Accepted 23 July 1985 sequential two minute intervals each for lungs, kidneys and brain, so that counting was completed 16 minutes after injection. The particles were measured by light microscopy, with an eye piece micrometer; the longest diameter was noted. Particles were found to be $11-60 \mu \mathrm{m}$ in diameter with a typical size distri-

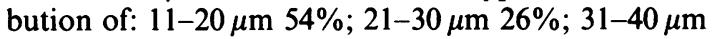
$16 \%$ (they were rarely greater than $40 \mu \mathrm{m}$ ). Any particles traversing the lungs to the systemic circulation would necessarily pass through vessels larger than $10 \mu \mathrm{m}$. The amount of radioactivity in the distribution of the systemic circulation was calculated on the assumption that at rest $32 \%$ of the cardiac output goes to brain and kidneys. ${ }^{8}$ The fractional amount of blood shunted is therefore the radioactivity in the systemic circulation divided by the sum of that radioactivity and that remaining in the lungs. If the patients with fibrosis were having long term oxygen or steroid treatment, this was continued during injection and scanning. All studies were performed with the subjects fasting. A chromatograph was used to test label activity, which was found to be less than $2 \%$ of untagged isotope in all instances. In the lung impacted particles break down and pass to the systemic circulation at a rate of about $11 \%$ in the first hour. Particle breakdown during scanning and untagged isotope cause a calculated shunt that is somewhat higher than that yielded when other forms of physiological measurement are used.

Eleven consecutive patients with pulmonary fibrosis were studied during a period of clinical stability. They were free of other major medical problems. Informed consent was obtained. The diagnosis of pulmonary fibrosis was proved by biopsy in six patients and based on the finding of chronic interstitial radiological shadowing and a compatible clinical picture in the other five. In pulmonary function tests, the single breath carbon monoxide technique was used for the measurement of diffusing capacity and nitrogen washout techniques for determination 


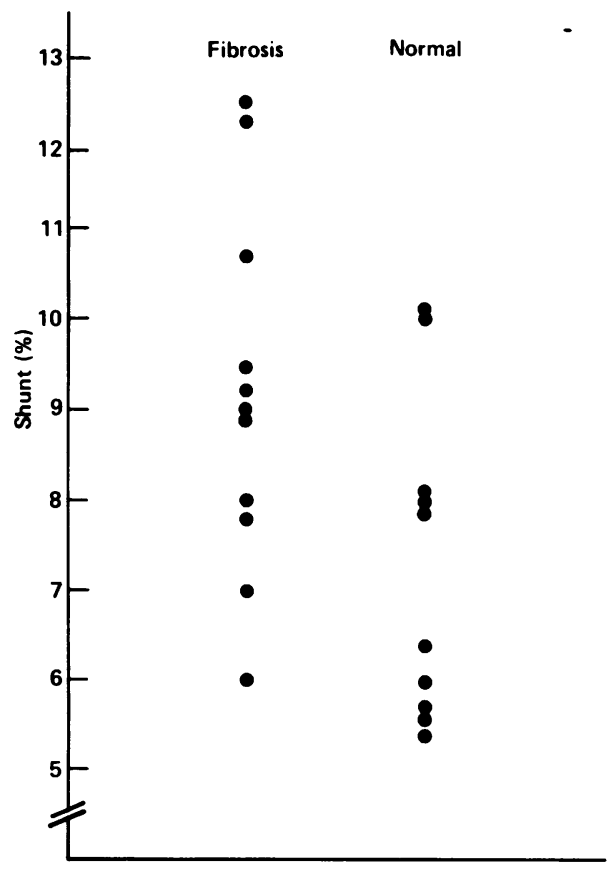

Pulmonary shunting in patients with fibrosis and normal subjects.

of functional residual capacity. Arterial blood gases were drawn at rest during the breathing of room airunfortunately sometimes in the sitting and sometimes in the supine position. Blood gas data obtained during exercise were not generally available. Results are reported as mean values with one standard deviation in parentheses. These patients had a total lung capacity of $71 \%(16 \%)$ of predicted, a vital capacity of $68 \%(20 \%)$ of predicted, and an alveolar-arterial oxygen tension difference of $36(15) \mathrm{mm} \mathrm{Hg}(4.8(2.3)$ $\mathrm{kPa})$. Tests for antinuclear antibody were positive in five of the 11 patients, and a test for rheumatoid factor was positive in one of the seven patients in which it was done. The patients were compared with 10 healthy non-smoking volunteers drawn from hospital and medical personnel. Statistical analysis was by Student's $t$ test for unpaired variables and by use of the correlation coefficient.

\section{Results}

The percentage shunt in the patients with fibrosis $(9.2 \% \quad(2.0 \%))$ was slightly higher but not significantly different from that measured in the normal subjects $(7.3 \%(1.8 \%))$. Individual data are depicted in the figure. The calculated shunt fell outside the $95 \%$ confidence interval for normal subjects in only two of the fibrosis patients-being higher in both instances. The magnitude of the shunt measured in the patients with fibrosis was found not be correlated with any index of pulmonary function or with the alveolar-arterial oxygen pressure difference.

\section{Discussion}

These data show little significant shunting through enlarged pulmonary vessels in most patients with pulmonary fibrosis. The findings are distinctly different from those from our studies in patients with chronic obstructive pulmonary disease, where a high incidence of shunting was found that was believed to explain in part the aggravation of hypoxaemia by exercise in those patients. The two studies proceeded largely concurrently, so we do not believe that systematic methodological errors account for the differences. As a group, patients with fibrosis were less physiologically impaired than the patients with chronic obstructive lung disease, but within the fibrosis group the level of physiological impairement bore no relation to the measured shunt. Obviously the pathogenesis of pulmonary fibrosis and chronic obstructive lung disease differ, and this may account for the differences in the patients we have studied. The results of previous studies suggest that hypoxaemia in patients with pulmonary fibrosis is largely due to classical ventilation-perfusion imbalance with minor contributions from diffusion impairment. ${ }^{9}$ Enlarged pulmonary vessels do not seem to play a part.

\section{References}

1 Wolfe JD, Tashkin DP, Holly FE, Brachman MB, Genovesi MG. Hypoxemia of cirrhosis. Detection of abnormal small pulmonary vascular channels by a quantitative radionuclide method. Am J Med 1977;63:746-54.

2 Davis HH, Schwartz DJ, Lefrak SS, Susman N, Schainker BA. Alveolar-capillary oxygen disequilibrium in hepatic cirrhosis. Chest 1978;73:507-11.

3 Miller WC, Heard JG, Unger KM. Enlarged pulmonary arteriovenous vessels in COPD. Chest 1984;86:704-6.

4 Kennedy TC, Knudson RJ. Exercise-aggravated hypoxemia and orthodeoxia in cirrhosis. Chest 1977;72:305-9.

5 Owens GR, Rogers RM, Pennock BE, Levin D. The diffusing capacity as a predictor of arterial oxygen disaturation during exercise in patients with chronic obstructive pulmonary disease. $N$ Engl J Med 1984;310: 1218-21.

6 Crystal RG, Falmer JD, Roberts WC, Moss ML, Line BR, Reynolds HY. Idiopathic pulmonary fibrosis. Ann Intern Med 1976;85:769-88.

7 Risk C, Epler GR, Gaensler EA. Exercise alveolararterial oxygen pressure difference in interstitial lung disease. Chest 1984;85:69-74.

8 Wade OL, Bishop JM. Cardiac output and regional blood flow. Oxford: Blackwell Scientific Publications, 1962:86.

9 Wagner PD, Dantzker DR, Dueck R, Depolo JL, Wasserman K, West JB. Distribution of ventilationperfusion ratios in patients with interstitial lung disease. Chest $1976 ; 69$, suppl:256-7. 